\title{
Erratum to: Information and Communication Technologies in Tourism 2017
}

\author{
Roland Schegg and Brigitte Stangl
}

\section{Erratum to:}

\section{R. Schegg and B. Stangl (eds.), Information} and Communication Technologies in Tourism 2017, DOI 10.1007/978-3-319-51168-9

The original version of the book was inadvertently published without the following corrections:

In Chapter "The Future of Wearable Devices On-Site: A Scenario Technique Approach", author name order should be changed from "Rincon, Fernanda Ortiz" to "Ortiz Rincon, Fernanda".

In Chapter "'Thank You for Your Stay," and Then What? Macau Hotels' Responses to Consumer Online Reviews', author name order should be changed from "Chen Ning (Chris)" to "Ning (Chris) Chen".

In Chapter "Do Local Residents and Visitors Express the Same Sentiments on Destinations Through Social Media?", Fig. 1 needs to be changed.

\footnotetext{
The updated original online version for this chapters can be found at

DOI 10.1007/978-3-319-51168-9_21

DOI 10.1007/978-3-319-51168-9_40

DOI 10.1007/978-3-319-51168-9_47
}

\author{
R. Schegg $(\square)$ \\ Institute of Tourism, HES-SO Valais-Wallis, Sierre, Valais, Switzerland \\ e-mail: roland.schegg@hevs.ch \\ B. Stangl \\ School of Hospitality and Tourism Management, University of Surrey, Guildford, UK \\ e-mail: b.stangl@surrey.ac.uk

